\title{
Competition and Facilitation in Hairy Vetch-Barley Intercrops
}

\author{
Giacomo Tosti*, Paolo Benincasa, Marcello Guiducci \\ Department of Agricultural and Environmental Science, University of Perugia \\ Borgo XX Giugno 74, 06121 Perugia, Italy
}

Received: 14 September 2009. Accepted: 24 November 2009.

\begin{abstract}
Intercrops between legumes and non-legumes are widely used for fodder production and as cover crops, but little quantitative data are available on competition between species in the mixture. The objective of the present study was to assess the interaction between hairy vetch (Vicia villosa Roth.) and barley (Hordeum vulgare L.) grown as pure crops or intercrops with different proportions of seed rates at sowing.

A 4-year field study was conducted using hairy vetch and barley as pure stands at full sowing density and as intercrops at different proportions of their own full seed rate according to the replacement principle. Interaction between species was evaluated on the basis of Land Equivalent Ratio (LER), Relative Neighbour Effect (RNE) and Aggressivity (A) calculated on biomass and nitrogen (N) accumulation.

The $\mathrm{N}$ accumulation of the mixed crops increased linearly with the legume proportion in the mixture. The mixtures were more efficient than the pure crops in terms of $\mathrm{N}$ use (LER $>1$ ). Partial LER values indicated that the barley component benefited from the presence of the legume, while the hairy vetch partial LER decreased with increasing barley proportion in the mixture.

The competitive response in terms of biomass accumulation was high for both species when their density in the mixture was high. Concerning $\mathrm{N}$ accumulation, barley benefited from an asymmetric interspecific facilitation while the vetch behaviour was similar to that observed for biomass accumulation.

Barley dominance progressively increased reaching a maximum just before the last sampling date. At the last sampling date the competitive ability of hairy vetch showed a considerable increase in all mixtures $(A \approx 0)$.

These findings indicate that the use of mixtures between hairy vetch and barley allows an increase in the use efficiency of $\mathrm{N}$ resource with respect to pure crops. Barley is the dominant component of the mixture and the hairy vetch is able to cope with the cereal competitive effect only at the end of the shooting phase of barley. Moreover when the soil $\mathrm{N}$ supply is high, the recovering ability of the vetch in the mixture could be strongly reduced. In such conditions, the proportion of legumes at sowing should be increased in order to counteract barley dominance and allow a late recovery of the legume component.
\end{abstract}

Key-words: Barley, Competition, Facilitation, Hairy Vetch, Intercropping, Mixtures.

\section{Introduction}

Intercropping is defined as the simultaneous growth of two or more species on the same physical space during a significant portion of their biological cycle (Ofori and Stern, 1987; Vandermeer, 1989).

The different behaviour of intercropped species is related to the ability of tolerate (competitive response) and affect (competitive ef- fect) neighbours (Goldberg and Werner, 1983). Such abilities are equally exerted by plants towards kin or non-kin species generating intraor inter-specific competition. The balance between intra- or inter-specific competition can result in a facilitative or competitive relationship between the intercropped species (Vandermeer, 1989). Interspecific facilitation implies that one crop alters the environment of the other in a positive direction so as to benefit the growth of 
the other species (Begon et al., 1996). When facilitation leads to an increase for one component and a decrease for the other, the interaction is defined as asymmetric interspecific facilitation. If the increase occurs for both component species the interaction is termed symmetric interspecific facilitation ( $\mathrm{Li}$ et al., 2003).

Actually the borders between the competition and facilitation are not so clear and they can occur at the same time (Hauggaard-Nielsen et al., 2001) or at different stages during the crop cycle (Zhang and Li, 2003).

Most studies on intercropping have focused on the widespread legume-cereal intercrop (Ofori and Stern, 1987; Fan et al., 2006), where the cereal components deplete nitrogen $(\mathrm{N})$ soil reserve and limit weeds growth (HauggaardNielsen, 2001), while the legume, normally the weaker competitor, enhances the use of atmospheric $\mathrm{N}_{2}$ by an improvement of its biological $\mathrm{N}$-fixation ability (Jensen, 1996). Other causes of performance increment are related to direct facilitative interaction (Hauggaard-Nielsen and Jensen, 2005); clear evidences are available on i) the ability of legumes to mobilize fixed $P$ from organic or soil compounds, respectively by extra-cellular enzymes or by $\mathrm{pH}$ lowering effect (Dakora and Phillips, 2002; Li et al., 2003); ii) the improvement of soil microbial biodiversity and the better soil aggregation thanks to the quantity and quality of legume root exudates (Haynes and Beare, 1997) and iii) the direct N transfer from legumes to the non-fixing component (Xiao et al., 2004) that seems really important and places a big challenge for its clarification (Høgh-Jensen, 2006).

Finally, the use of legumes in mixtures is also a useful tool for reducing the dependence of conventional agriculture from synthetic-N (Jensen and Hauggaard-Nielsen, 2003; Crews and Peoples, 2004; Nilabja, 2004) and it could play a crucial role in $\mathrm{N}$ management in organic farming systems.

Several indices such as Land Equivalent Ratio (De Wit and Van den Bergh, 1965), Relative Neighbour Effect (Markham and Chanway, 1996) and Aggressivity (McGilchrist, 1965) have been developed to describe competition in intercropping, however these indices have not been used yet in intercropping systems involving hairy vetch (Vicia villosa Roth.) and barley (Hordeum vulgare L.), two of the most impor- tant species for intercrops in the Mediterranean environment. Moreover, it has been widely discussed how the density at which intercrop components are sown may be of great significance in determining the production efficiency of cereal-legume intercrops, and how the changes in the proportion of component species could alter the competition dynamics (Willey and Osiru, 1972; Hauggaard-Nielsen et al., 2006). Nevertheless, only few studies (Caballero et al., 1995; Lithourgidis et al., 2006; Dhima et al., 2007) have used these indices to describe the interspecific and intra-specific competition dynamics as affected by the sowing density of the components in the intercrop.

The objectives of this study were to: i) estimate the effect of competition between hairy vetch and barley grown in three mixtures with different seeding ratios, and (ii) assess which system is more efficient, based on competition indices.

\section{Materials and methods}

\section{Experimental Site and Crop Management}

Field experiments were carried out in four consecutive years (from 2004/2005 to 2007/2008) at the Experimental Station of the Department of Agricultural and Environmental Sciences of the University of Perugia, located in Papiano, Italy $\left(43^{\circ} \mathrm{N}, 165 \mathrm{~m}\right.$ a.s.l.) on a silty-loam soil with $1.3 \%$ organic matter content in the top soil ( 0 $0.4 \mathrm{~m})$.

Weather data were obtained from an automatic meteorological station inside the experimental site. The precipitation surplus/deficit throughout the crop cycle was estimated as the difference between daily precipitation and potential evapotranspiration calculated following the Penman-Monteith method (Fig. 1).

Hairy vetch (Vicia villosa Roth.) and barley (Hordeum vulgare L.) were cultivated as pure crops at full sowing density (200 seeds of vetch $\mathrm{m}^{-2}, \mathrm{~V} 100 ; 400$ seeds of barley $\left.\mathrm{m}^{-2}, \mathrm{~B} 100\right)$ and as intercrops. In intercrops, species were combined with different seed ratios according to the replacement principle (De Wit and van den Bergh, 1965; Connolly, 1986) where the seed rate of each component is a proportion of the full rate used in monocultures, keeping the sum of the proportions as 100 . The following three combinations 


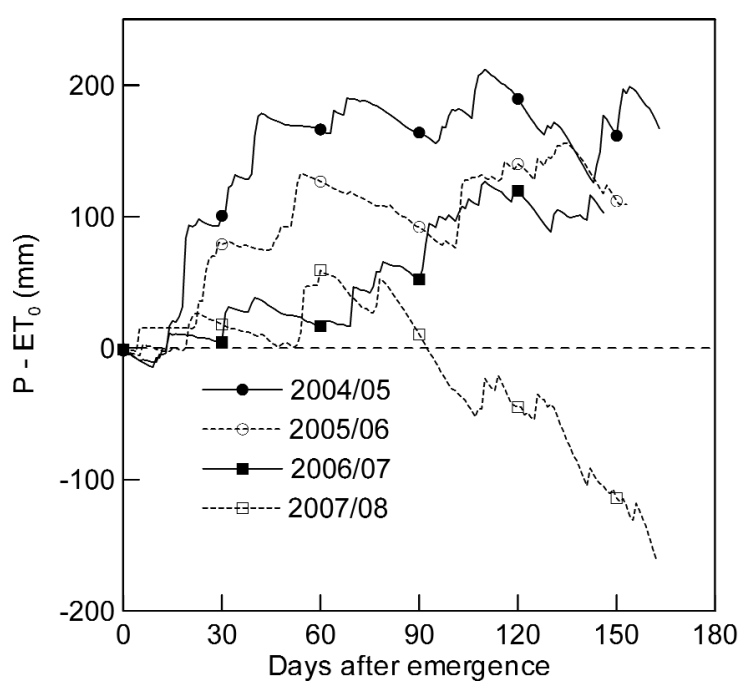

Figure 1. Cumulated difference between daily precipitation $(\mathrm{P})$ and Penman-Monteith crop evapotranspiration $\left(\mathrm{ET}_{0}\right)$ during the crop cycle.

were adopted: vetch at $75 \%$ of its own full seed rate + barley at $25 \%$ of its own seed rate (V75B25), vetch 50\% + barley 50\% (V50B50) and vetch $25 \%$ + barley $75 \%$ (V25B75).

Pure crops and mixtures were always sown at the beginning of November in single rows $0.15 \mathrm{~m}$ apart. Barley and vetch in the mixtures were sown in the same row, so the contact between them was maximised. Plant emergence always occurred regularly about two weeks after sowing. No fertilisation was supplied and the crops were managed according to organic practices.

\section{Plant sampling and analyses}

Above-ground biomass accumulation was determined by periodical samplings of plants from $0.5 \mathrm{~m}^{2}$ per plot. In 2005-2006 the plants were sampled 6 times: 63, 91, 126, 140, 147, 154 Days After Emergence (DAE). In 2006-2007 they were sampled 5 times: 35, 69, 112, 127, 146 DAE. In 2004-2005 and 2007-2008 plants were sampled only at the end of the crop cycle, at 161 and 162 DAE, respectively.

At each sampling date vetch and barley in mixtures were separated by hand. Plant biomass was then oven dried at $80{ }^{\circ} \mathrm{C}$. Sub-samples of the dry material were ground to a fine powder for the analysis of $\mathrm{N}$ content. An automatic analyser (FlowSys, Systea, Italy) was used to measure reduced-N concentrations in Kjeldhal digests prepared following the method proposed by Isaac and Johnson (1976).

\section{Competition indices and statistics}

The effect of the interaction between the species in a mixture was calculated using different competition indices. The Land Equivalent Ratio (LER) was used as the criterion for mixed stand advantage/disadvantage. LER is defined as the relative land area growing pure crops that is required to produce the yields achieved when growing intercrops (Willey, 1979). In this experiment, the LER was calculated on the $\mathrm{N}$ uptake rather than on the biomass yield of the component species. LER for a barley-hairy vetch intercrop is the sum of the partial LER values for barley $\left(\operatorname{LER}_{\mathrm{B}}\right)$ and hairy vetch $\left(\mathrm{LER}_{\mathrm{V}}\right)$, in accordance with De Wit and Van den Bergh (1965):

$$
\begin{gathered}
L E R=\left(L E R_{B}+L E R_{V}\right) ; \\
L E R_{B}=\frac{P_{B V}}{P_{B}} ; L E R_{V}=\frac{P_{V B}}{P_{V}}
\end{gathered}
$$

where $\mathrm{P}_{\mathrm{BV}}$ and $\mathrm{P}_{\mathrm{VB}}$ are the performances as intercrops and $\mathrm{P}_{\mathrm{B}}$ and $\mathrm{P}_{\mathrm{V}}$ are performances as pure crops of barley and hairy vetch, respectively. LER $>1$ indicates an advantage from intercropping in terms of the use of environmental resources for plant growth. LER $<1$ indicates resources are used more efficiently by pure crops than by intercrops.

The Relative Neighbour Effect (RNE) (Markham and Chanway, 1996; Bartelheimer et al., 2006) was used to assess the competitive interaction between the species. The RNE is a measure of the effect of neighbours relative to the plant with the greatest performance. The RNE is calculated as:

$$
R N E=\frac{\left(P_{\text {control }}-P_{m i x}\right)}{x}
$$

with

$$
\begin{gathered}
x=P_{\text {control }} \text { when } P_{\text {control }}>P_{\text {mix }} \\
x=P_{\text {mix }} \text { when } P_{\text {control }}>P_{\text {mix }}
\end{gathered}
$$

where $\mathrm{P}$ is the plant performance in the absence $\left(\mathrm{P}_{\text {control }}\right)$ and in the presence $\left(\mathrm{P}_{\text {mix }}\right)$ of a neighbour. Dry weight accumulation and $\mathrm{N}$ uptake of the component species at final sampling date were chosen as performance parameters. 
The RNE ranges from -1 to +1 , with negative values indicating facilitation and positive values indicating competition.

Aggressivity index measures how much the performance of one component species is greater than that of the other in a mixture (McGilchrist, 1965). The aggressivity indices for barley $\left(A_{B}\right)$ and for hairy vetch $\left(A_{V}\right)$ were calculated as:

$A_{B}=\frac{P_{B V}}{P_{B} S_{B V}}-\frac{P_{V B}}{P_{V} S_{V B}} ; A_{V}=\frac{P_{V B}}{P_{V} S_{V B}}-\frac{P_{B V}}{P_{B} S_{B V}}$

where the biomass accumulation in pure crops $\left(\mathrm{P}_{\mathrm{B}}\right.$ and $\left.\mathrm{P}_{\mathrm{V}}\right)$ and in mixtures $\left(\mathrm{P}_{\mathrm{BV}}\right.$ and $\left.\mathrm{P}_{\mathrm{VB}}\right)$ are used as performance parameter. $\mathrm{S}_{\mathrm{BV}}$ and $\mathrm{S}_{\mathrm{VB}}$ are the proportions at sowing of barley and vetch in mixture, respectively. If $A_{B}=A_{V}=0$, both species are equally competitive, if $A_{B}>0$ (i.e. $A_{V}<0$ ) then barley is the dominant species, while if $A_{B}$ $<0$ (i.e. $A_{V}>0$ ) then barley is the dominated species (i.e. vetch is the dominant one).

Treatments were compared on a randomized block design with 3 replicates in 2004/2005 and 2007/2008, 8 replicates in 2005/2006 and 6 repli- cates in 2006/2007. Within year, means were separated by Fisher's protected Least Significant Difference at $\mathrm{P}=0.05$ probability level. Only statistically significant effects will be noted on the text.

\section{Results}

Cumulated precipitation over the entire crop cycle (November to March) were much variable among years. The first year was characterized by intense rainfall, while the last one was very dry. The difference between precipitations and Penman-Monteith evapotranspiration was very high in 2004/05 and in 2005/06 until DAE 60, moderate in 2006/07, very low and negative from 90 DAE onwards in 2007/08 (Fig. 1). As a consequence, nitrate loss from the rooting zone due to deep drainage and/or denitrification was expected to be intense in the first two years, moderate in 2006/07 and negligible in the last year.

In all years, the highest $\mathrm{N}$ accumulation was observed in pure vetch (Fig. 2). In the first three years the $\mathrm{N}$ accumulation of vetch plants was substantially proportional to the sowing density

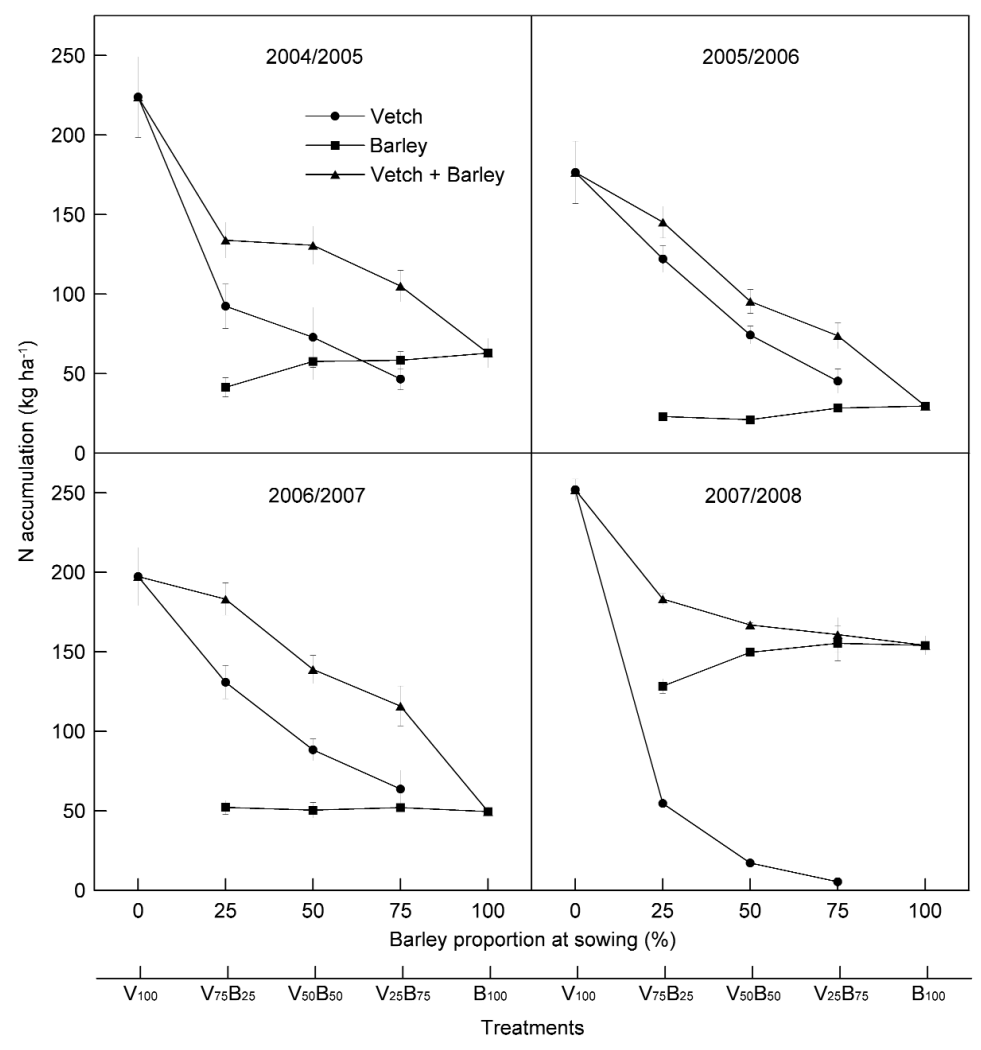

Figure 2. Total $\mathrm{N}$ accumulation at final harvest versus barley seed proportion at sowing in vetch and barley grown in pure stand at full sowing density (V100 and B100, respectively) and in mixtures obtained using different fractions of the full sowing densities of each component species: $75 \%$ vetch $+25 \%$ barley (V75B25), 50\% + 50\% (V50B50) and $25 \%+75 \%$ (V25B75). Bars represent \pm S.E. 


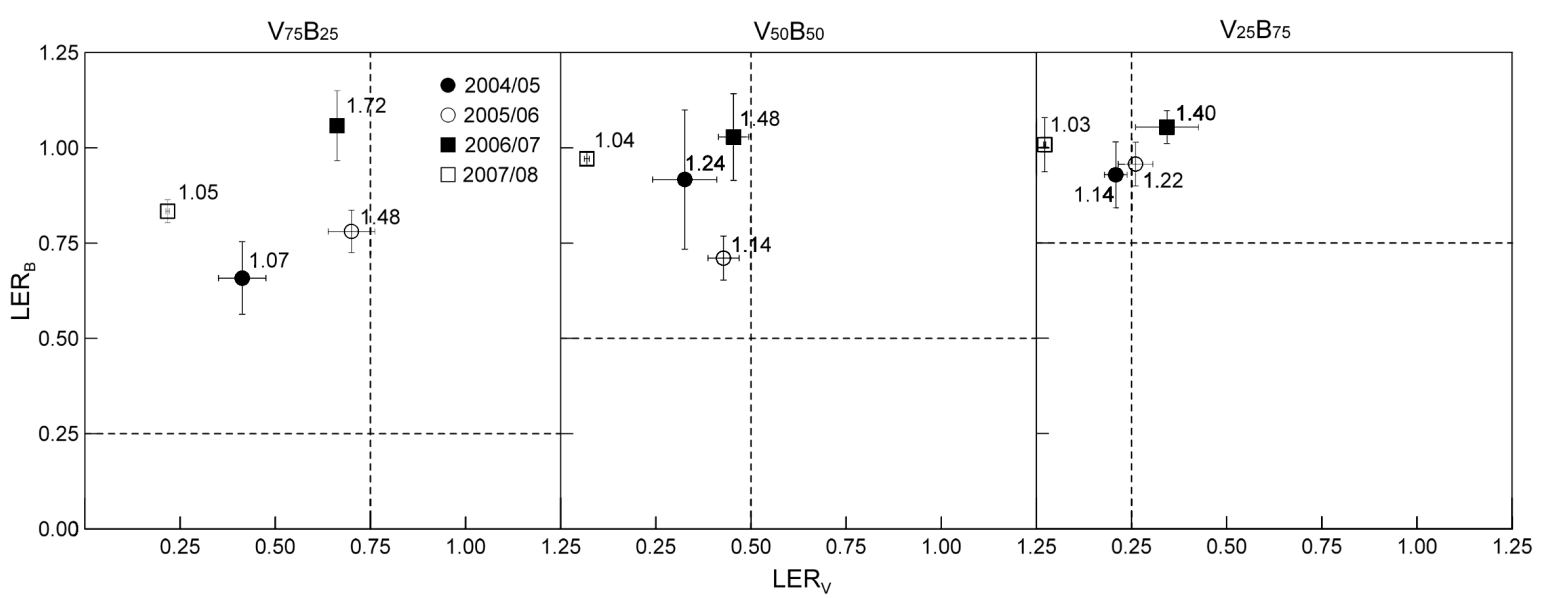

Figure 3. Partial Land Equivalent Ratios (LER) for $\mathrm{N}$ accumulation of vetch $\left(\mathrm{LER}_{\mathrm{V}}\right)$ versus partial LER of barley $\left(\mathrm{LER}_{\mathrm{B}}\right)$ in four consecutive years in mixtures obtained using different fractions of the full sowing densities of each component species: $75 \%$ vetch $+25 \%$ barley (V75B25), 50\% + 50\% (V50B50) and 25\% + 75\% (V25B75). Labels are the total LER $\left(\mathrm{LER}_{\mathrm{V}}+\mathrm{LER}_{\mathrm{B}}\right)$ recorded in each year and mixture. Dotted lines indicate limit values for LER $\mathrm{L}_{\mathrm{V}}(\mathrm{ver}-$ tical line) and $\mathrm{LER}_{\mathrm{B}}$ (horizontal line) in the case of neutral interaction between the species. Bars represent \pm S.E.

of vetch (i.e. V100 > V75B25 > V50B50> V25B75), while the $\mathrm{N}$ accumulated by barley plants was always low and quite stable, with no significant differences among treatments.

In 2007/2008, N accumulation of pure vetch was similar to that recorded in the previous years while it was very low in mixtures. On the contrary $\mathrm{N}$ accumulation of barley plants showed a threefold increase with respect to previous years.

In all years and in all intercrops, LER values were $>1$ (Fig. 3). The sowing density did not show any effect on the partial LER of barley $\left(\mathrm{LER}_{\mathrm{B}}\right)$ as it was constantly higher than the corresponding relative seeding proportion (neutral interaction: $\mathrm{LER}_{\mathrm{B}}>0.75$ in V25B75, $>0.50$ in V50B50 and > 0.25 in V75B25). Partial LER of hairy vetch $\left(\mathrm{LER}_{\mathrm{V}}\right)$ increased as the proportion of barley in the mixture decreased and it was lower than the corresponding relative seeding proportion (i.e. $<0.25$ in $\mathrm{V} 25 \mathrm{~B} 75,<0.5$ in V50B50 and $<0.75$ in V75B25) excepted in V25B75 in 2006/07 (Fig. 3). The LER $_{V}$ was just slightly under the above-mentioned limits in the first three years, while in 2007/2008 the reduction of $\mathrm{N}$ accumulation of vetch was very strong in all mixtures, therefore $\mathrm{LER}_{\mathrm{V}}$ was very low, approaching zero in V50B50 and V25B75 (Fig. 3).

The RNE relative to dry weight accumulation $\left(\mathrm{RNE}_{\mathrm{DW}}\right)$ in both barley and vetch was strictly proportional to the biomass proportion of each species in the mixtures (Fig. 4). When
$\mathrm{N}$ accumulation was considered as performance parameter $\left(\mathrm{RNE}_{\mathrm{N}}\right)$, an asymmetric interspecific facilitation was observed for barley. The $\mathrm{RNE}_{\mathrm{N}}$ of vetch showed similar results as for $R_{N E}$, while the $\mathrm{RNE}_{\mathrm{N}}$ of barley approximated zero and was not related to the proportion of barley biomass in the mixture (Fig. 4).

The asymmetric interspecific facilitation led to an increase of the $\mathrm{N}$ concentration $(\mathrm{N} \%)$ of barley grown in mixture with respect to pure stand barley. Such an increase was linearly related to the vetch seeding proportion (Fig. 5).

The sequential measurements of crop growth carried out in 2005/2006 and 2006/2007 were used to assess which of the two species was the dominant component of the mixture and for how long during the growing cycle (Fig. 6). In 2006/2007, the Aggressivity index for barley $\left(A_{B}\right)$ was generally higher than in 2005/2006, nevertheless the general behaviour was similar: the lower was the proportion of barley in the mixture at sowing, the higher was the relative advantage respect to the performance of the pure barley stand.

In both years, barley was the dominant species $\left(A_{B}>0\right)$. Barley dominance progressively increased during the growing cycle, reaching a maximum just before the last sampling date. At the end of the crop cycle the competitive ability of hairy vetch showed a considerable increase in all mixtures, especially in 


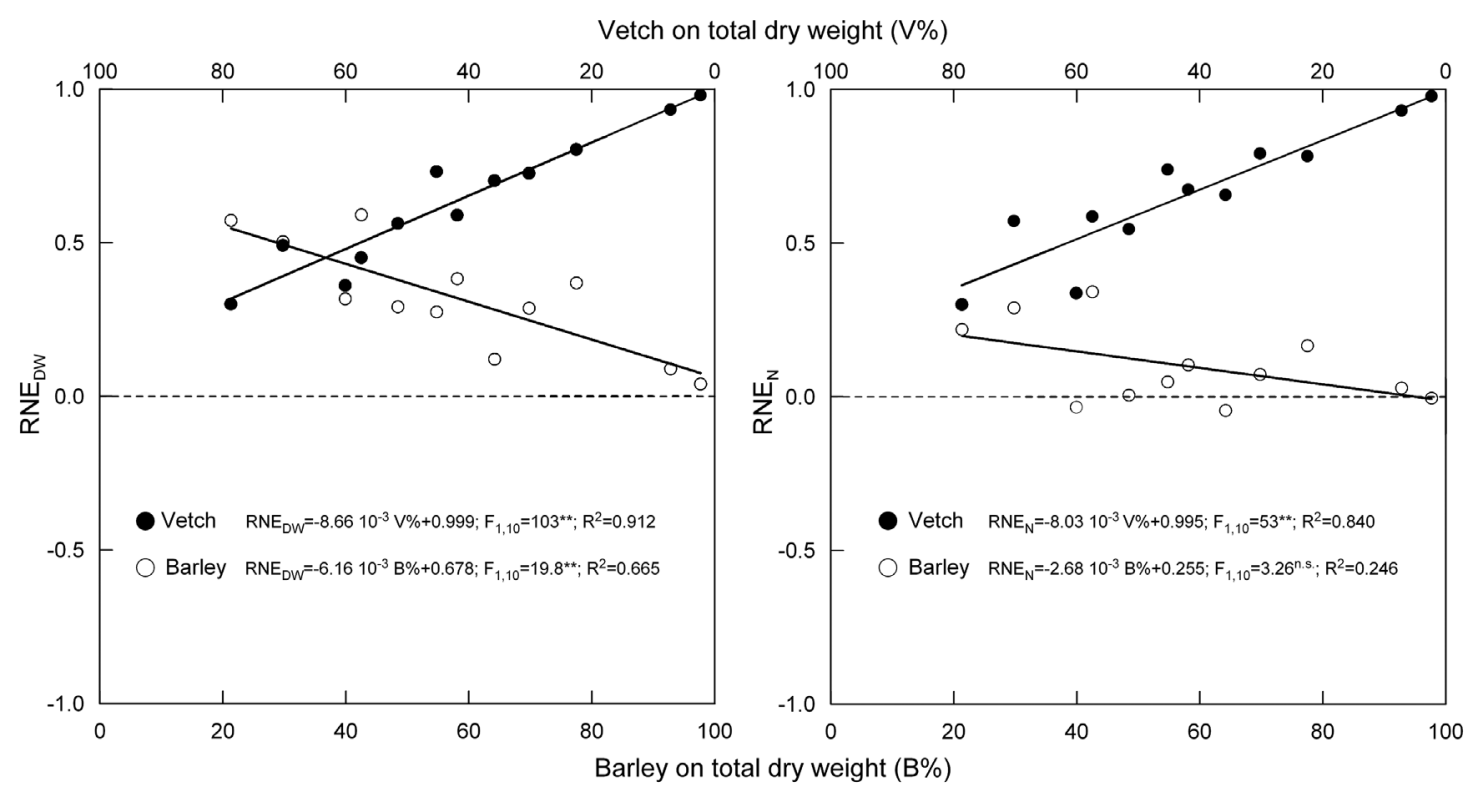

Figure 4. Overall relationships between Relative Neighbour Effect for vetch and barley calculated on either final dry weight $\left(\mathrm{RNE}_{\mathrm{DW}}\right.$, left) or $\mathrm{N}$ accumulation $\left(\mathrm{RNE}_{\mathrm{N}}\right.$, right) in mixtures and the proportion of each species on total dry weight at final harvest. Dotted lines represent neutral interaction between component species $(\mathrm{RNE}=0)$. Linear regressions are reported in figures.

$\mathrm{F}$ test significant for $\mathrm{P} \leq 0.01(* *)$ or not significant (n.s.).

$\mathrm{V} 50 \mathrm{~B} 50$ and in V25B75, where the $\mathrm{A}_{\mathrm{B}}$ was reduced to zero (i.e. both species equally competitive).

\section{Discussion}

Hairy vetch showed a substantially different $\mathrm{N}$ accumulation capacity in the three different mixtures while barley did not (Fig. 2). This indicates that the hairy vetch-barley mixture is a competitive intercropping system from the legume perspective; such results are in agreement with many other studies (Danso et al., 1987; Brandsæter and Netland, 1999; Ghaley et al., 2005) where legumes were found to be the weaker competitor as compared to the cereal.

In all the mixtures total LER was higher than 1 , which shows the advantages of intercropping over pure crops in terms of $\mathrm{N}$ use (Fig. 3). As stated by Jensen (1996) the potential advantages gained from intercropping are determined by the degree of complementary resource use between the component species. However, in our experiment, the different mixtures behaved differently: the lowest barley proportion was particularly effective on raising
LER values, while decreasing LER values were found in mixture with high barley sown proportion.

Such findings are confirmed by the relationships between RNE and the proportion of the single component species in the mixtures (Fig. 4). According to Goldberg and Fleetwood (1987), interspecific competition could be divided into competitive effect and competitive response. The competitive effect of barley towards vetch was similar for $\mathrm{N}$ and dry matter accumulation. On the contrary, the competitive response of barley was quite different for $\mathrm{N}$ with respect to dry matter accumulation, being the $\mathrm{N}$ accumulation not affected by the competitive effect of the legume. As a consequence, the best combination in terms of $\mathrm{N}$ use efficiency was achieved when both species showed the lowest $\mathrm{RNE}_{\mathrm{N}}$ (i.e. when vetch proportion was the highest in the mixture).

Due to the stronger competitive ability for soil mineral $\mathrm{N}$ of the cereal compared with the legume (Haynes, 1980; Jensen, 1996), barley grown in mixture benefited from having access to a more than proportionate share of the soil $\mathrm{N}$ resources (Ghaley et al., 2005; HauggaardNielsen et al., 2006). However, the high com- 


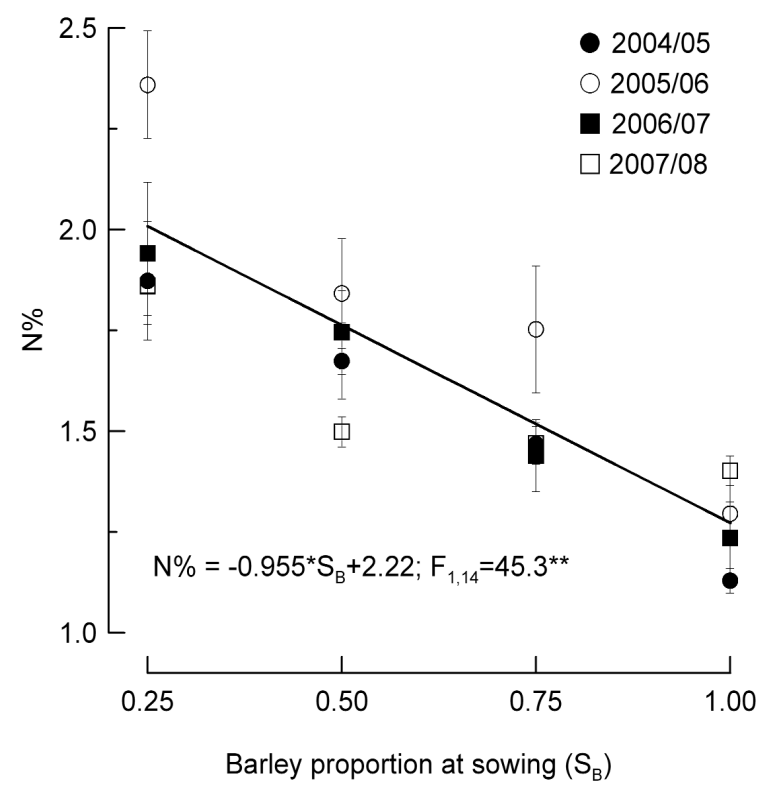

Figure 5. Nitrogen concentration on barley dry matter at final sampling date $(\mathrm{N} \%)$ as affected by barley seed proportion at sowing $\left(\mathrm{S}_{\mathrm{B}}\right)$. Linear regression calculated over all experimental years is reported. Bars represent \pm S.E. $\mathrm{F}$ test significant for $\mathrm{P} \leq 0.01(* *)$.

petitive ability for soil $\mathrm{N}$ exerted towards the legume is also effective on barley itself, leading to a strong intra-specific competition. The intraspecific competition for $\mathrm{N}$ had an effect on the barley $\mathrm{N}$ uptake per plant that was significantly greater for intercropped compared to pure cereal. The low $\mathrm{N} \%$ recorded in pure barley and the linear increase of $\mathrm{N} \%$ with the increasing proportion of the hairy vetch in the mixed stand crop confirm the role of intra-specific competition among barley plants (Fig. 5).
As stated by Zhang and Li (2003) the interspecific competition and facilitation occurs at the same time. The best advantage in terms of $\mathrm{N}$ use efficiency was, in fact, observed in those mixtures that showed the highest relative increase of barley $\mathrm{N}$ accumulation during the plant growth cycle, i.e. in mixtures where the highest barley dominance was observed (Fig. 6).

In all the mixtures there was an increase in hairy vetch Aggressivity index at the end of the cycle. Such an increase was probably due to the positive effect of the cereal that, at the end of shooting, stopped its fast growth allowing the creeping legume to prolong its growth period by using the barley plants as stakes. In this way, the legume partially compensated for the impaired early growth following the "competitive-recovery production principle" (Zhang and $\mathrm{Li}, 2003$ ).

The balance between the component species was greatly affected by environmental conditions. In 2007/2008, the competitive effect of barley was much high because the low rainfall recorded in this year reduced the $\mathrm{N}$ loss from the rooting zone (Fig. 1). In that year the high $\mathrm{N}$ availability stimulated barley which thus suppressed the hairy vetch growth (Fig. 2-3). Therefore, the proportion of the component species set at sowing radically changed during the growth cycle as the legume was not able to respond to the highly aggressive barley plants.

\section{Conclusions}

The use of mixtures between hairy vetch and barley allowed an increase in the use efficiency

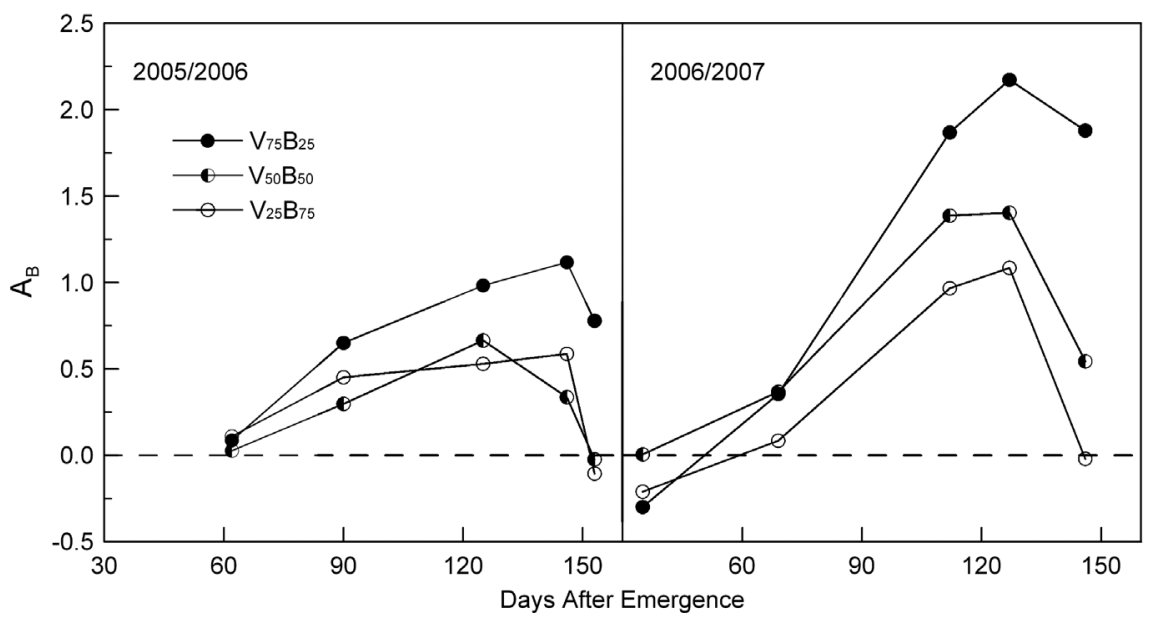

Figure 6. Time course of Aggressivity index for barley $\left(A_{B}\right)$ in $2005 / 2006$ and $2006 / 2007$ in the mixtures obtained using different fractions of the full sowing densities of the component species: $75 \%$ vetch $+25 \%$ barley (V75B25), 50\% + $50 \%$ (V50B50) and 25\% + $75 \%$ (V25B75). 
of $\mathrm{N}$ resource with respect to pure stand crops. Barley was the dominant component of the mixture and hairy vetch was able to cope with the cereal competitive effect only at the end of the shooting phase of barley. When environmental conditions prevented the vetch recovery, the efficiency of the mixtures were strongly reduced. The recovering ability of the vetch in the mixture was depressed in a dry year, when the mineral $\mathrm{N}$ availability in the soil was likely high. This suggests that when the mineral $\mathrm{N}$ in the soil is expected to be high, the proportion of legumes at sowing should be increased in the mixture in order to counteract barley dominance and allow a late recovery of the legume component.

\section{Acknowledgment}

We would like to thank the technical staff of the Experimental Station of Papiano for their invaluable support.

Research funded by the FISR SIMBIO-VEG (2005-08).

\section{References}

Bartelheimer M., Steinlein T., Beyschlag W. 2006. Aggregative root placement: a feature during interspecific competition in inland sand-dune habitats. Plant Soil, 280:101-114.

Begon M., Harper J.L., Townsend C.R. 1996. Ecology, individuals, populations and communities. Blackwell Science, London, UK. 1068 pp.

Brandsæter L.O., Netland J. 1999. Winter annual legumes for use as cover crops in row crops in northern regions: I. Field experiments. Crop Sci., 39:1369-1379.

Caballero R., Goicoechea E.L., Hernaiz P.J. 1995. Forage yields and quality of common vetch and oat sown at varying seeding ratios and seeding rates of common vetch. Field Crop. Res., 41:135-140.

Connolly J. 1986. On difficulties with replacement-series methodology in mixture experiments. J. Appl. Ecol., 23:125-137.

Crews T., Peoples M. 2004. Legume versus fertilizer sources of nitrogen: ecological tradeoffs and human needs. Agricult. Ecosys. Environ., 102:279-297.

Dakora F., Phillips D. 2002. Root exudates as mediators of mineral acquisition in low-nutrient environments. Plant Soil, 245:35-47.

Danso S., Zapata F., Hardarson G., Fried M. 1987. Nitrogen fixation in fababeans as affected by plant population density in sole or intercropped systems with barley. Soil Biol. Biochem., 19: 411-415.
De Wit C.T., van der Berg J.P. 1965. Competition between herbage plants. Neth. J. Agric. Sci., 13:212-221.

Dhima K., Lithourgidis A., Vasilakoglou I., Dordas C. 2007. Competition indices of common vetch and cereal intercrops in two seeding ratio. Field Crop. Res., 100:249-256.

Fan F., Zhang F., Song Y., Sun J., Bao X., Guo T., Li L. 2006. Nitrogen fixation of faba bean (Vicia faba L.) interacting with a non-legume in two contrasting intercropping systems. Plant Soil, 283: 275-286.

Ghaley B., Hauggaard-Nielsen H., Hogh-Jensen H., Jensen E.S. 2005. Intercropping of wheat and pea as influenced by nitrogen fertilization. Nutr. Cycl. Agroecosys., 73:201-212.

Goldberg D.E., Fleetwood L. 1987. Competitive effect and response in four annual plants. J. Ecol., 75:11311143.

Goldberg D.E., Werner P.A. 1983. Equivalence of competitors in plant communities: a null hypothesis and a field experimental approach. Am. J. Bot., 70:10981104.

Hauggaard-Nielsen H., Jensen E.S. 2005. Facilitative root interactions in intercrops. Plant Soil, 274:237-250.

Hauggaard-Nielsen H., Ambus P., Jensen E.S. 2001. Interspecific competition, $\mathrm{N}$ use and interference with weeds in pea-barley intercropping. Field Crop. Res., 70:101-109.

Hauggaard-Nielsen H., Andersen M., Jornsgaard B., Jensen E.S. 2006. Density and relative frequency effects on competitive interactions and resource use in pea-barley intercrops. Field Crop. Res., 95:256-267.

Haynes R., Beare M. 1997. Influence of six crop species on aggregate stability and some labile organic matter fractions. Soil Biol. Biochem., 29:1647-1653.

Haynes R.J. 1980. Competitive aspects of the grasslegume association. Adv. Agron., 33:227-261.

Hogh-Jensen H. 2006. The nitrogen transfer between plants: an important but difficult flux to quantify. Plant Soil 282:1-5.

Isaac R.A., Johnson W.C. 1976. Determination of total nitrogen in plant tissue, using a block digestor. Journal of the AOAC, 59:98-100.

Jensen E.S. 1996. Grain yield, symbiotic $\mathrm{N}_{2}$ fixation and interspecific competition for inorganic $\mathrm{N}$ in pea-barley intercrops. Plant Soil, 182: 25-38.

Jensen E.S., Hauggaard-Nielsen H. 2003. How can increased use of biological $\mathrm{N}_{2}$ fixation in agriculture benefit the environment? Plant Soil, 252:177-186.

Li L., Tang C.X., Rengel Z., Zhang F.S. 2003. Chickpea facilitates phosphorus uptake by intercropped wheat from an organic phosphorus source. Plant Soil, 248:297-303.

Lithourgidis A.S., Vasilakoglou I.B., Dhima K.V., Dordas C.A., Yiakoulaki M.D. 2006. Forage yield and quality of common vetch mixtures with oat and triticale in two seeding ratios. Field Crop. Res., 99:106-113. 
Markham J., Chanway C. 1996. Measuring plant neighbour effects. Funct. Ecol., 10:548-549.

McGilchrist C.A. 1965. Analysis of competition experiments. Biometrics, 21:975-985.

Nilabja G. 2004. Reducing dependence on chemical fertilizers and its financial implications for farmers in India. Ecol. Econom., 49:149-162.

Ofori F., Stern W.R. 1987. Cereal-legume intercropping systems. Adv. Agron., 41:41-90.

Vandermeer J. 1989. The ecology of intercropping. Cambridge University Press, Cambridge, UK. 237 pp.

Willey R.W. 1979. Intercropping - its importance and re- search needs. Part I. Competition and yield advantages. Field Crop. Abstr., 32:2-10.

Willey R.W., Osiru D.S. 1972. Studies on mixtures of maize and beans (Phaseolus vulgaris) with particular references to plant population. J. Agric. Sci., 79:519-529.

Xiao Y., Li L., Zhang F. 2004. Effect of root contact on interspecific competition and $\mathrm{N}$ transfer between wheat and faba bean using direct and indirect ${ }^{15} \mathrm{~N}$ techniques. Plant Soil, 262:45-54.

Zhang F., Li L. 2003. Using competitive and facilitative interactions in intercropping systems enhances crop productivity and nutrient-use efficiency. Plant Soil, 248:305-312. 
